\title{
Desnaturação da clara do ovo: um experimento simples de Bioquímica para o ensino
}

\section{de Biologia}

Denaturation of egg white: a simple Biochemistry experiment for teaching Biology

Desnaturalización de la clara de huevo: un sencillo experimento de bioquímica para la enseñanza de la Biología

Tiago Maretti Gonçalves

\begin{abstract}
Resumo
As proteínas constituem uma das moléculas mais importantes e incríveis da vida. No entanto, quando expostas a condições adversas como variação de temperatura, $\mathrm{pH}$ e até mesmo solventes orgânicos, elas sofrem desnaturação, alterando sua forma e perdendo sua função. O presente artigo possui como principal objetivo propor uma aula prática para facilitar a aprendizagem do tema de desnaturação proteica aos alunos do ensino médio, na disciplina de Biologia. Para isso, serão utilizados como recursos, materiais simples e de baixo custo como a clara de um ovo de galinha, copinhos descartáveis ou tubos de ensaio transparentes, vinagre (ácido acético) e álcool 70\%. Submetendo a albumina (proteína presente na clara do ovo) em diferentes tratamentos, os alunos irão verificar se esta irá se desnaturar ou não, discutindo e resgatando os conceitos teóricos aprendidos previamente na disciplina de Biologia. Desta maneira, acreditamos que, a prática da experimentação científica aliada com as discussões mediadas pelo professor permitirão potencializar a aprendizagem dos alunos no tópico proposto, desmistificando-se assim que a Bioquímica é uma área complexa.
\end{abstract}

Palavras-chave: Aula experimental; Proteínas; Ensino; Desnaturação.

\begin{abstract}
Proteins are one of the most important and incredible molecules in life. However, when exposed to adverse conditions such as temperature variation, $\mathrm{pH}$ and even organic solvents, they undergo denaturation, changing their shape and losing their function. This article has as main objective to propose a practical class to facilitate the learning of the protein denaturation theme to high school students, in the discipline of Biology. For this, simple and low-cost material resources will be used, such as the white of a hen's egg, disposable cups or transparent test tubes, vinegar (acetic acid) and $70 \%$ alcohol. By submitting albumin (protein present in egg whites) in different treatments, students will check whether it will denature or not, discussing and rescuing the theoretical concepts previously learned in the discipline of Biology. In this way, we believe that the practice of scientific experimentation combined with discussions mediated by the teacher can enhance the students learning in the proposed topic, thus demystifying that Biochemistry is a complex area.
\end{abstract}

Keywords: Experimental class; Proteins; Teaching; Denaturation.

\section{Resumen}

Las proteínas son una de las moléculas más importantes e increíbles de la vida. Sin embargo, cuando se exponen a condiciones adversas como variación de temperatura, $\mathrm{pH}$ e incluso disolventes orgánicos, se desnaturalizan, cambian de forma y pierden su función. Este artículo tiene como objetivo principal proponer una clase práctica para facilitar el aprendizaje del tema desnaturalización de proteínas a estudiantes de secundaria, en la disciplina de Biología. Para ello se utilizarán recursos materiales sencillos y de bajo coste, como claras de huevo de gallina, vasos desechables o probetas transparentes, vinagre (ácido acético) y alcohol al 70\%. Al presentar albúmina (proteína presente en las claras de huevo) en diferentes tratamientos, el alumno comprobará si desnaturaliza o no, discutiendo y rescatando los conceptos teóricos aprendidos previamente en la disciplina de Biología. De esta forma, creemos que la práctica de la experimentación científica combinada con discusiones mediadas por el docente puede potenciar el aprendizaje de los estudiantes en el tema propuesto, desmitificando así que la Bioquímica es un área compleja.

Palabras clave: Clase experimental; Proteínas Enseñando; Desnaturalización. 


\section{Introdução}

Proteínas são componentes essenciais a todas as células vivas (Quiroga, 2014), e são estruturas de grande importância, desempenhando diversas funções dentro dos seres vivos, como o transporte, proteção, controle e regulação, catálise e movimento e até mesmo armazenamento de substâncias com a função por exemplo de reserva energética (Koolamn e Rohm, 2008). Na verdade, a importância das proteínas é enfatizada pelo nome, que vem da palavra grega proteios, que significa "primeiro" ou "primário". Proteínas são responsáveis por mais mais de 50\% da massa seca da maioria das células e elas são fundamentais nas atividades dos organismos (Carvalho \& Recco-Pimentel, 2013; Urry et al., 2021).

Quimicamente, as proteínas são definidas como cadeias longas de aminoácidos unidos por ligações peptídicas (amida), com a inserção de um grupo amina contendo nitrogênio carregado positivamente em uma extremidade e um grupo carboxila com carga negativa na outra extremidade (Campbel, 2008).

Na Biologia, as proteínas são objetos de estudo da Bioquímica, uma área fascinante que possui como principal objetivo o estudo das moléculas da vida. (Nelson e Cox, 2018). Segundo Voet, Voet e Pratt (2016), essa área é integradora de muitas outras disciplinas como a biologia celular, genética, imunologia, microbiologia, farmacologia e fisiologia. Estando presente até mesmo na descrição de processos patológicos, fornecendo explicações ao nível molecular para as doenças do ser humano (Marshall \& Lapsley, 2016).

No entanto, essa área é encarada pelos alunos como complexa por deter uma grande quantidade de termos e conteúdos que devem ser muito bem contextualizados. Na literatura, Duré, Andrade e Abílio (2018), relataram que a Bioquímica é uma das áreas mais rejeitadas pela concepção de mais de 180 alunos do ensino médio, obtendo-se assim um índice de 43,4\% de rejeição. Não obstante, os autores constataram que existe uma grande dificuldade dos alunos em contextualizar a Bioquímica com a vida cotidiana, ressaltando-se ainda mais essa barreira.

Para vencermos tais obstáculos e permitir uma maior aceitação da Bioquímica, facilitando sua aprendizagem pelos discentes é de grande importância a proposta de metodologias alternativas de ensino, e uma delas é a abordagem de aulas experimentais (Gonçalves, 2021a; 2021b). Contudo, de maneira geral, as instituições públicas de ensino, não dispõem de infraestrutura física, equipamentos de segurança e materiais necessários para a realização desses experimentos (Salesse, 2012), uma vez que segundo dados do Instituto Nacional de Estudos e Pesquisas Educacionais Anísio Teixeira - INEP (2019), apenas 38,8\% das escolas públicas no Brasil possuem laboratórios de Ciências e Biologia para o desenvolvimento de aulas práticas. Assim, vale a pena ressaltarmos que essas são uma das razões motivadoras para a realização da proposta desse trabalho. Deste modo, a abordagem da experimentação científica utilizando-se materiais alternativos e de baixo custo favorecem a construção do aprendizado e potencializa o interesse do aluno na área da Bioquímica.

Segundo Silva, Sales e Anjos (2021), as aulas práticas são peças fundamentais no ensino de Ciências e Biologia, permitindo ao docente utilizar diferentes materiais disponíveis aos alunos, promovendo a aprendizagem significativa. Desta forma, as autoras ressaltam ainda que a abordagem de aulas práticas pode viabilizar o conhecimento científico baseado na indução e dedução de acordo com o conhecimento prévio de cada aluno. Corroborando com este pensamento, Trindade et al, (2021) apontam que as aulas experimentais são fundamentais para uma aprendizagem significativa, onde os conceitos científicos poderão ser aplicados no cotidiano de cada aluno. Já, Gonçalves (2021b) salienta que a abordagem de aulas práticas pode ser de grande importância, pois facilita o processo de ensino-aprendizagem dos alunos, transpondo na prática o que foi aprendido na aula teórica em sala de aula.

Desta forma, o principal objetivo deste trabalho é a proposta de uma aula prática para facilitar a aprendizagem dos alunos do ensino médio na disciplina de Biologia, no assunto de constituição química da célula (desnaturação de proteínas) 
utilizando materiais simples e de baixo custo. Nesta dinâmica, os alunos poderão fortalecer o que foi aprendido nas aulas teóricas de Biologia, auxiliando os discentes na construção do conhecimento. Vale a pena ressaltarmos que a atividade prática proposta permite ao professor trabalhar outros conteúdos de Biologia como a Embriologia (anexos embrionários) e aspectos nutricionais relacionados as propriedades do ovo como um alimento de grande importância presente na mesa dos brasileiros. A atividade possui duração média de realização de 30 minutos, sendo direcionada aos alunos do primeiro ano do ensino médio.

\section{Metodologia}

A atividade proposta possui caráter qualitativo com uma abordagem didático-experimental possuindo base metodológica proposta por Pereira et al. (2018). O protocolo experimental proposto é originado a partir de experimentações prévias. Fica a cargo do professor ajustá-lo conforme suas necessidades, como por exemplo, a inclusão de outros tratamentos com o intuito de enriquecer as discussões geradas por meio da realização da atividade prática.

\subsection{Materiais necessários para a condução da atividade}

Para a realização da aula prática proposta serão necessários os seguintes materiais:

- 1 ovo de galinha de onde será reservado o conteúdo de sua clara;

- Tubos de ensaio ou copos de café descartáveis transparentes;

- Microondas ou fogão;

- Vinagre caseiro (Ácido acético);

- Álcool 70\%;

- Caneta de retroprojetor;

- Seringas de $5 \mathrm{ml}$ (facilmente adquirida em farmácias).

\subsection{Realizando a atividade: preparo e preenchimento dos copinhos descartáveis transparentes/tubos}

Os copinhos descartáveis transparentes ou tubos de ensaio deverão ser enumerados e preenchidos conforme constam no quadro a seguir.

Quadro 1. Legendas das xícaras/tubos e preenchimento dos tratamentos.

\begin{tabular}{|c|c|}
\hline NUMERAÇÕES DAS COPINHOS/TUBOS & TRATAMENTOS \\
\hline 1 & Água $(2 \mathrm{ml})+$ Clara de ovo $(3 \mathrm{ml})-$ Controle da reação; \\
\hline 2 & Clara de ovo $(3 \mathrm{ml})$ aquecida durante 10 segundos no micro-ondas; \\
\hline 3 & Vinagre $(2 \mathrm{ml})+$ Clara de ovo $(3 \mathrm{ml}) ;$ \\
\hline 4 & Álcool $(2 \mathrm{ml})+$ Clara de ovo $(3 \mathrm{ml})$ \\
\hline
\end{tabular}

Fonte: Autor.

No tubinho de número 2, aquecer a clara do ovo durante 10 segundos no micro-ondas. Se for optar pelo fogão, pedir auxílio para um adulto para evitar queimaduras. Nesse sentido, pode ferver um pouco de água e adicionar 3 ml desta no copinho com a clara de ovo. Após o preenchimento de todos os tratamentos, esperar alguns minutos para o acontecimento das 
reações. Sugerir aos alunos que registrem por meio de um relatório o que aconteceu em cada um dos copinhos/tubos, formulando-se assim as hipóteses, para posterior discussão com o professor.

\section{Resultados e discussão com abordagens da atividade no escopo da biologia}

Como fruto da presente atividade, o que podemos evidenciar nos tubos de ensaio submetidos aos diferentes tratamentos? Na Figura 1, temos as transformações ocorridas em cada um deles.

Figura 1. Clara de ovo de galinha submetidas à diferentes tratamentos. 1a. Controle; 1b. Aquecimento e clara de ovo, 1c. Vinagre e clara de ovo e 1d. Ácool $70 \%$ e clara de ovo.

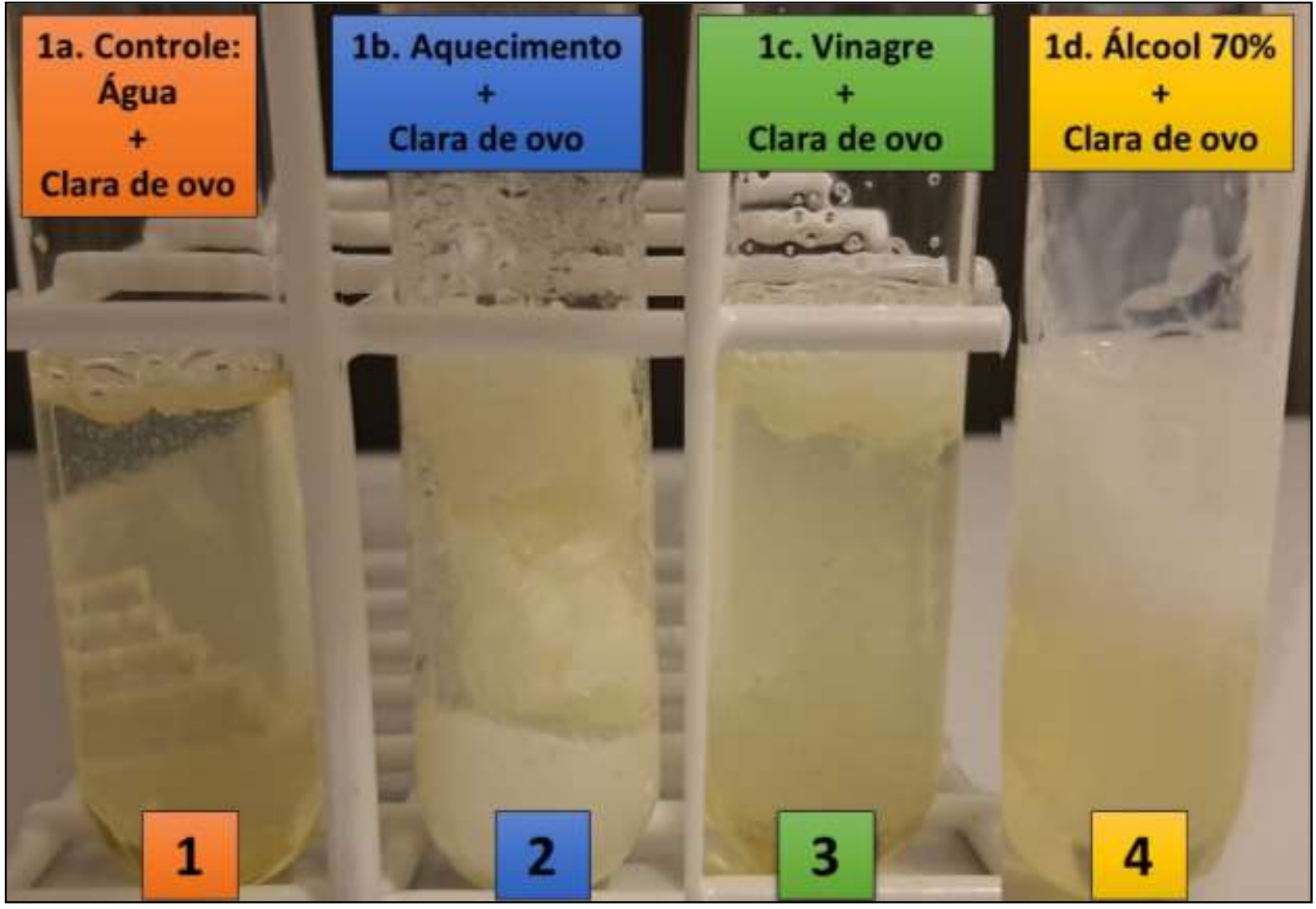

Fonte: Autor.

No tubo de ensaio 1, o nosso controle, é composto por água e clara de ovo. Nesse tratamento nada ocorreu. Chamar a atenção dos alunos que esse tratamento é de grande importância. Nos experimentos laboratoriais o tratamento controle possui como principal papel eliminar possíveis interferências externas, validando a condução do experimento. Nesse caso, a clara do ovo está intacta, líquida e transparente (Figura 1a).

Já no tubo de ensaio 2, o aquecimento do meio fez com que ocorresse a mudança da textura da clara de ovo, acarretando sua desnaturação. Explicar aos alunos que a temperatura elevada pode ocasionar a alteração na estrutura das proteínas, e no caso do experimento proposto, o calor desnaturou as proteínas da albumina presente na cala do ovo, desnaturando e alterando sua estrutura, que comparada ao controle fica branca e rígida, ou seja, endurecida (Figura 1b).

No tubo de ensaio 3, a adição de vinagre na clara de ovo ocasionou a mudança brusca de $\mathrm{pH}$ do meio, alterando assim 
a atração das cargas elétricas da proteína. Assim, como resultado a proteína da albumina presente na clara se desnaturou e precipitou na fase superior do tubo, chamar a atenção dos alunos para o aspecto branco no formato de uma massa sólida (Figura 1c).

No tubo número 4, o álcool $70 \%$ promoveu a desnaturação da albumina, fazendo com que essa macromolécula se precipite, adquirindo uma coloração branca (Figura 1d). Nessa parte do experimento, o professor pode complementar o resultado, explicando aos alunos a importância da higienização das mãos com o álcool 70\%, uma vez que ele atua na atividade microbicida, sendo eficaz contra bactérias, fungos e vírus, sendo eficaz também na prevenção da transmissão do novo coronavírus (Galante, 2020). Neste sentido, o álcool na diluição de $70 \%$ possui concentração ótima para a desnaturação de proteínas do microrganismo, pois na presença de água a sua entrada na célula é facilitada e a volatilização do álcool é retardada, permitindo maior tempo de contato. Dessa forma, a destruição da membrana celular externa do microrganismo ocorre por desidratação na presença de álcool, uma vez que o álcool é higroscópico e hidrofílico. Em sequência, as moléculas de álcool penetram no citoplasma causando a precipitação de proteínas por desnaturação, promovendo também a coagulação de enzimas responsáveis por atividades celulares essenciais, levando a morte do microorganismo (Kampf \& Kramer, 2004; Nigro et al., 2020).

Como esse experimento utiliza materiais simples e de baixo custo e não necessita ser realizado necessariamente em um laboratório de Biologia, ele é fortemente recomendado para o ensino atual, uma vez que as aulas estão seguindo o parâmetro a distância de ensino (modalidade virtual), em detrimento a pandemia do novo coronavírus. Assim, sua abordagem e realização possui resultados enriquecedores, uma vez que o aluno pode na sua própria casa replicar o experimento explicado previamente pelo professor, garantindo ao aluno aliar a teoria com a prática, facilitando sua aprendizagem no tema proposto.

Esse experimento ilustra de maneira clara, simples e eficaz o processo de desnaturação proteica da albumina na clara do ovo. Deve ser ressaltado aos alunos que os fatores como o aumento da temperatura (fervura), variações bruscas de pH do meio e solventes orgânicos como o álcool 70\% contribuem para "atrapalhar" as interações intermoleculares das proteínas causando sua desnaturação. Assim segundo Nelson e Cox (2018) a desnaturação é definida como a perda da conformação proteica nativa que é especificada por meio de sua cadeia polipeptídica, ocasionando a perda de sua função. Segundo os autores, o fator temperatura atua rompendo as interações fracas das proteínas, no caso por exemplo as pontes de hidrogênio.

Aprofundando nos fatores que causam a desnaturação das proteínas, iniciamos com o aumento da temperatura, que pode ser visualizado no tubo número 2. Neste fator, é de grande relevância discutir com os alunos que existem diversas proteínas que suportam temperaturas muito altas, que são denominadas termoestáveis, assim, como exemplo pode ser discutido que existem bactérias denominadas de termofílicas que vivem em fontes de águas termais, suportando altas temperaturas em torno de 100 graus (Nelson \& Cox, 2018). No que tange ao fator pH, exemplificado pelo tubo 3, ocorreu um aumento do número de íons $\mathrm{H}^{+}$no meio em detrimento da adição do vinagre (ácido acético). Dessa forma, é interessante explicar aos alunos que nenhuma ligação covalente é quebrada. Com a adição do vinagre, irá ocorrer a alteração na carga líquida da proteína de albumina, causando repulsão eletrostática e ruptura de algumas pontes de hidrogênio, ocasionando sua precipitação e desnaturação. Já no fator solventes, o álcool (tubo de número 4), atua rompendo as interações hidrofóbicas das proteínas, levando sua estrutura ao processo de desnaturação, perdendo sua função (Nelson \& Cox, 2018). Neste sentido, Flores et al. (2019) ao adicionar $20 \mathrm{ml}$ de álcool etílico na clara do ovo, a mesma se tornou esbranquiçada pela precipitação das proteínas que se desnaturaram, retornando a ter apenas uma conformação em cadeia simples de aminoácidos.

Fora do escopo da Bioquímica, a atividade prática proposta, permite ao professor trabalhar com os alunos o assunto de Embriologia (anexos embrionários), tendo o ovo de galinha como exemplo. Assim segundo Júnior e Sasson (2005), durante o desenvolvimento embrionário dos vertebrados, ocorrem algumas membranas anexas originadas dos folhetos embrionários, 
Research, Society and Development, v. 10, n. 3, e47010313779, 2021

(CC BY 4.0) | ISSN 2525-3409 | DOI: http://dx.doi.org/10.33448/rsd-v10i3.13779

desempenhando funções importantes como proteção, nutrição, excreção, respiração e outras. O professor pode chamar a atenção dos principais anexos embrionários presentes no ovo de galinha (ave), explicando suas funções (Quadro 2).

Quadro 2. Legendas das xícaras/tubos e preenchimento dos tratamentos.

\begin{tabular}{|c|c|}
\hline ANEXOS & FUNÇÃO DO ANEXO EMBRIONÁRIO. \\
\hline Saco vitelino & Fornece e armazena reservas nutritivas para o desenvolvimento do embrião. \\
\hline Córion & $\begin{array}{c}\text { Proporciona trocas respiratórias ao embrião por meio das membranas do poro da } \\
\text { casca do ovo. }\end{array}$ \\
\hline Âmnio & Manutenção da umidade e proteção do embrião. \\
\hline Alantóide & Armazenamento de excretas. \\
\hline
\end{tabular}

Fonte: Autor.

Outra discussão que pode ser feita é sobre os aspectos nutricionais do ovo na nossa dieta. De acordo com, Carolino et al. (2018), o ovo de galinha é considerado um alimento natural de destacado valor nutritivo e de baixo custo. Os ovos são uma importante fonte de proteínas, de baixo teor calórico e de fácil digestibilidade para a dieta humana, pelo que são consumidos pelas várias faixas etárias, sendo um dos poucos alimentos ingeridos em todo o mundo. Conforme Neves e Henry (2012), a gema do ovo possui proteínas de alto valor biológico, ácidos graxos essenciais, fosfolipídeos e glicerol. Já a clara, possui $88,5 \%$ de água, $13,5 \%$ de proteínas, $11 \%$ de gorduras, hidratos de carbono e a Riboflavina, que é uma vitamina do complexo B, além de possuir as vitaminas A, D, E e K (FAO, 2010; Carolino et al., 2018).

Na literatura, Gonçalves (2021b), publicou uma proposta de atividade experimental de Bioquímica para os alunos do ensino médio. Nessa atividade prática, o autor simula a digestão de proteínas de colágeno da gelatina por meio do uso de enzimas digestivas presentes em frutas tropicais como o mamão (enzima papaína) e o abacaxi (enzima bromelina), o sachê de enzimas digestivas e o amaciante de carne caseiro. Neste sentido, essa aula prática também se desponta como sendo de grande importância no ensino das proteínas, pois alia na prática o que foi aprendido nas aulas teóricas de Biologia. Em detrimento da pandemia do novo coronavírus, essa atividade pode ser replicada pelos alunos em suas próprias casas, pois utiliza materiais simples, caseiros e de baixo custo independentemente da existência de um laboratório físico de Biologia ou de Ciências.

Para avaliar a aprendizagem da aula prática, no próximo tópico é proposto algumas questões que poderão ser respondidos pelos alunos no fim da atividade prática e entregue ao professor para correção. Como as aulas estão seguindo o modelo virtual de ensino, em detrimento do novo coronavírus, essa atividade prática pode ser demonstrada virtualmente pelo professor aos alunos, que em suas casas poderão replicar o experimento. Assim, em um próximo encontro, o professor pode discutir as respostas e sanar as possíveis dúvidas com os alunos. No tópico 5, encontram-se as respostas esperadas das questões. No quadro abaixo, está disposto um resumo dos conteúdos que essa atividade permite ser trabalhada com os alunos. 
Research, Society and Development, v. 10, n. 3, e47010313779, 2021

(CC BY 4.0) | ISSN 2525-3409 | DOI: http://dx.doi.org/10.33448/rsd-v10i3.13779

Quadro 3. Conteúdos trabalhados pela proposta experimental.

\begin{tabular}{|c|c|}
\hline ASSUNTO & DETALHAMENTO DA ABORDAGEM \\
\hline \multirow{2}{*}{ Bioquímica } & - Desnaturação das proteínas; \\
& - Fatores que levam a desnaturação proteica; \\
& - Estrutura e função das proteínas. \\
\hline Embriologia & - Estrutura e função dos ovos de galinha; \\
Nutrição e & - Anexos embrionários. \\
Dieta & - Importância da ingestão de ovos e proteínas na dieta; \\
\hline
\end{tabular}

Fonte: Autor.

\section{Questões Propostas}

1) O que aconteceu em cada um dos tubos/xícaras? Formule uma hipótese para explicar os fenômenos ocorridos.

2) No nosso corpo humano, a febre é um fenômeno muito desagradável que serve para tentar eliminar os possíveis agentes infecciosos que por ventura podem estar em contato com o organismo. Como a febre pode estar relacionada com esse experimento da clara de ovo (albumina)?

3) Se ao invés de adicionarmos álcool $70 \%$ no tubo de número 4 , for adicionado clorofórmio, o que você esperaria que ocorresse? Justifique sua resposta.

4) (UFPB/2010) A figura a seguir mostra algumas estruturas embrionárias anexas do embrião das aves.

Figura 2. Estruturas embrionárias anexas do embrião de aves.

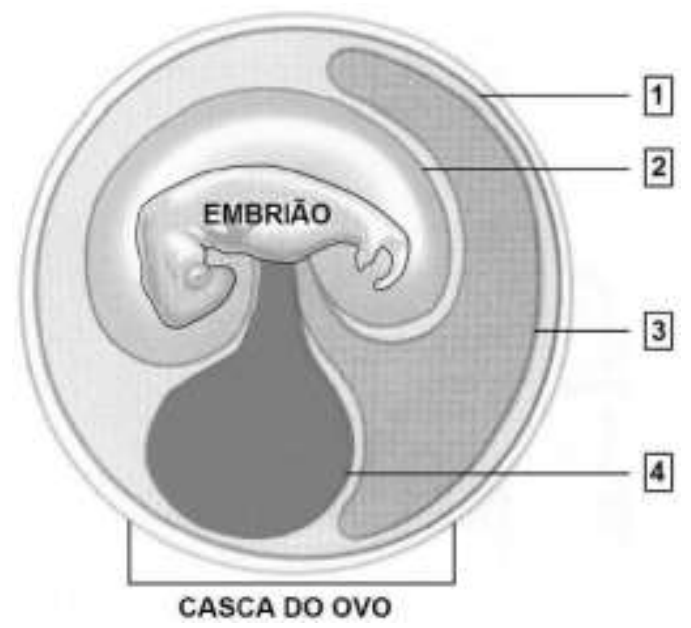

Fonte: adaptado de: Amabis e Martho (2004). Biologia das Células, Moderna, v. 1, p. 418.

Considerando as estruturas embrionárias anexas, é correto afirmar:

a) A estrutura 1 tem função principal de promover trocas gasosas entre o embrião e o ambiente. 
b) A estrutura 1 é a primeira membrana extraembrionária a ser formada.

c) A estrutura 2 é um líquido protetor do embrião contra desidratação.

d) A estrutura 3 não participa das trocas gasosas entre o embrião e o ambiente.

e) A estrutura 4 protege o embrião contra choques mecânicos.

5) Explique em linhas gerais como ocorre a desnaturação proteica. Uma proteína desnaturada, pode voltar a renaturarse?

\section{Respostas Esperadas das Questões}

1) Sugestão de hipóteses: O aquecimento, o vinagre e o álcool desempenham transformações nas ligações intracadeias nas proteínas, provocando a desnaturação das mesmas. $\mathrm{O}$ fator aquecimento, $\mathrm{pH}$, e solventes atuam interferindo a estrutura tridimensional das proteínas, podendo desnaturá-las. No quadro abaixo estão descritos os resultados do experimento.

Quadro 4. Resultados do experimento.

\begin{tabular}{|c|c|}
\hline $\begin{array}{c}\text { TUBOS/COPOS } \\
\text { DESCARTÁ VEIS }\end{array}$ & RESULTADOS \\
\hline 1 & Água $(2 \mathrm{ml})+$ Clara de ovo $(3 \mathrm{ml})$, é o controle da reação, nada ocorreu. \\
\hline 2 & $\begin{array}{r}\text { Clara de ovo }(3 \mathrm{ml}) \text { aquecida durante } 10 \text { segundos no micro-ondas, ocorreu cozimento } \\
\text { e por conseguinte desnaturação da albumina, mudando o aspecto da clara do ovo. }\end{array}$ \\
\hline 3 & $\begin{array}{r}\text { Vinagre }(2 \mathrm{ml})+\text { Clara de ovo (3 ml): ocorreu desnaturação e precipitação das } \\
\text { proteínas de albumina (parte branca), pelo vinagre. }\end{array}$ \\
\hline 4 & Álcool (2 ml) + Clara de ovo (3 ml): \\
\hline
\end{tabular}

Fonte: Autor.

2) A febre é uma tentativa do corpo em eliminar os patógenos que estão infectando o organismo humano elevando-se a temperatura corporal. Essa elevação pode causar a desnaturação das proteínas, podendo acarretar sérios problemas no corpo humano. Assim, a febre se relaciona com o experimento abordado, principalmente no que tange ao tratamento do aquecimento da clara de ovo, causando sua desnaturação.

3) Ocorreria o mesmo resultado, uma vez que o clorofórmio é um solvente anfipático como o álcool 70\%, capaz de desnaturar proteínas.

4) letra A.

5) A desnaturação proteica é o mecanismo de perda de função das proteínas em detrimento a fatores externos como o calor elevado, a variação brusca de pH do meio e o efeito de solventes na sua estrutura. Se sua estrutura não for totalmente alterada, e voltar as condições naturais do meio, a proteína pode voltar a se renaturar. 
Research, Society and Development, v. 10, n. 3, e47010313779, 2021

(CC BY 4.0) | ISSN 2525-3409 | DOI: http://dx.doi.org/10.33448/rsd-v10i3.13779

\section{Considerações Finais}

Pela aula prática proposta, os discentes poderão observar que diversos fatores como a temperatura, influência do pH, E solventes como o álcool 70\%, podem ocasionar a desnaturação proteica da proteína albumina presente na clara do ovo de galinha. Dessa forma, a realização da aula prática sugerida possui grande potencial metodológico qualitativo para facilitar a aprendizagem da temática proposta, resgatando na prática o que foi aprendido nas aulas teóricas, na disciplina de Biologia.

Além disso, a prática proposta pode permitir ao docente resgatar outros assuntos dentro da Biologia como os anexos embrionários (Embriologia) e aspectos relacionados a nutrição do ovo, como um alimento popularmente importante na nossa dieta.

Como sugestão futura, será de grande relevância a proposta de outros experimentos no escopo da Bioquímica de proteínas como a ação de enzimas proteolíticas naturais (papaína e bromelina) encontradas em frutas cotidianas como o mamão e o abacaxi, na degradação da gelatina (colágeno).

\section{Referências}

Amabis e Martho, Biologia das células, Moderna, v.1, p. 418.

Carolino, I., Cid, J., Lordelo, M., Ribeiro, V., Alves, S., Bessa, R., \& Carolino. N. (2018). Composição química dos ovos de galinhas de raças autóctones. https://vozdocampo.pt/2018/03/12/composicao-quimica-dos-ovos-de-galinhas-de-racas-autoctones/

Campbell, M. K. (2008). Bioquímica. (3a ed.), Artmed.

Carvalho, H. F., \& Recco-Pimentel, S. M. (2013). A Célula, (3a ed.), Manole.

Duré, R. C., Andrade, M. J. D., \& Abílio, F. J. P. (2018). Ensino de biologia e contextualização do conteúdo: quais temas o aluno de ensino médio relaciona com o seu cotidiano? Experiências em Ensino de Ciências. 13(1), 259-272. https://if.ufmt.br/eenci/artigos/Artigo_ID471/v13_n1_a2018.pdf

FAO. (2010). Agribusiness Handbook - Poultry Meat \& eggs. http://www.fao.org/docrep/012/al175e/al175e.pdf

Flores, G. R. M., Ruzzi, L. M., Bruzadelli, R. F. C., Silva, C. M. S., Piza, W. A, Silva, M. I., Paula, A. G., Almeida, C. S., Neto, E. G., \& Ribeiro, I. S. (2019). Desnaturação proteica: prática pedagógica aplicada no programa de monitoria de ensino. In Júnior, J. M. B. O., \& Calvão, L. B. (Orgs.). Debate e Reflexão das novas tendências da Biologia. Ponta Grossa, PR: Atena Editora. https://www.atenaeditora.com.br/post-artigo/18860

Galante, A. C. (2020). Farmácia universitária no combate ao novo coronavírus. https://xn--extenso-2wa.ufrj.br/images/Mat\%C3\%A9rias /farmacia/Materia_Farmacia_Universitaria.pdf

Gonçalves, T. M. (2021a). A guerra imunológica das células contra os patógenos: a proposta de um modelo didático tridimensional de baixo custo para simulação da resposta imune celular mediada por linfócitos $\mathrm{T}$ CD8+. Brazilian Journal of Development, 7(1), 4.854-4.860. https://www.brazilianjournals.com/index.php/BRJD/article/view/23099/18554

Gonçalves, T. M. (2021b). Ensinando Biologia em tempos de pandemia: um laboratório caseiro com materiais simples e de baixo custo para a simulação da digestão de proteínas. Educação Pública, 21(5). https://educacaopublica.cecierj.edu.br/artigos/21/5/ensinando-biologia-em-tempos-de-pandemia-umlaboratorio-caseiro-com-materiais-simples-e-de-baixo-custo-para-a-simulacao-da-digestao-de-proteinas

Instituto Nacional de Estudos e Pesquisas Educacionais Anísio Teixeira (2019). Dados do censo escolar. http://portal.inep.gov.br/artigo//asset_publisher/B4AQV9zFY7Bv/content/dados-do-censo-escolar-noventa-e-cinco-por-cento-das-escolas-de-ensino-medio-tem-acesso-a-internet-masapenas-44-tem-laboratorio-de-ciencias/21206

Júnior, C. S., \& Sasson, S. (2005). Biologia: volume 2: Seres vivos: estrutura e função. (8a ed.), Saraiva.

Kampf, G., \& Kramer, A. (2004). Epidemiologic background of hand hygiene and evaluation of the most important agents for scrubs and rubs. Clinical Microbiology Reviews. 17(4), 863-893. https://www.ncbi.nlm.nih.gov/pmc/articles/PMC523567/

Koolman, J., \& Röhm, K. H. (2008). Bioquímica - Texto e Atlas. (3a ed.), Artmed.

Marshal, W. J., \& Lapsley, M. (2016). Uso de dados bioquímicos na medicina clínica. In Marshal, W. J., Lapsley, M., Day, A. P., \& Ayling, R. M. (Ed.). Bioquímica Clínica: aspectos clínicos e metabólicos, (3a ed.), Elsevier.

Nelson, D. L., \& Cox, M. M. (2018). Princípios de Bioquímica de Lehninger, (7a ed.), Artmed.

Nigro, F., Tavares, M., Sato de Souza de Bustamante Monteiro, M., Toma, H. K., Faria de Freitas, Z. M., de Abreu Garófalo, D., Geraldes Bordalo MontáAlverne, M. A., Barros Dos Passos, M. M., Pereira Dos Santos, E., \& Ricci-Júnior, E. (2021). Changes in workflow to a University Pharmacy to facilitate compounding and distribution of antiseptics for use against COVID-19. Research in social \& administrative pharmacy, 17(1), 1997-2001. https://doi.org/10.1016/j.sapharm.2020.09.016 
Research, Society and Development, v. 10, n. 3, e47010313779, 2021

(CC BY 4.0) | ISSN 2525-3409 | DOI: http://dx.doi.org/10.33448/rsd-v10i3.13779

Pereira A. S., Shitsuka, D. M., Parreira, F. J., \& Shitsuka, R. (2018). Metodologia da pesquisa científica. [e-book]. Santa Maria. Ed. UAB/NTE/UFSM. https://repositorio.ufsm.br/bitstream/handle/1/15824/Lic_Computacao_Metodologia-Pesquisa-Cientifica.pdf?sequence=1.

Quiroga, A. L. B. (2014). Proteínas. Revista Food Ingredients Brasil FiB, 28, $30-58 . \quad$ https://revistafi.com.br/upload_arquivos/201606/2016060879641001464957906.pdf

Salesse, A. M. T. (2012). A experimentação no ensino de química: importância das aulas práticas no processo de ensino aprendizagem. Monografia de especialização (Educação: Métodos e Técnicas de Ensino, Modalidade de Ensino a Distância), Universidade Tecnológica Federal do Paraná. Medianeira, Paraná, Brasil. http://repositorio.roca.utfpr.edu.br/jspui/bitstream/1/4724/1/MD_EDUMTE_II_2012_21.pdf

Silva, L. O., Sales, R. A., \& Anjos, E. T. A. (2020). A aplicação de aulas práticas no ensino de ciências e biologia: uma análise crítica. Revista Philologus. 26(78), 52-63.

Trindade, I. T. M., Yamashita, E. F. R., Silva, L. P., Souza, E. A., Correa, G. M., \& Carmo, D. F. M. (2021). Aprendendo química no ensino médio através da separação de pigmentos por cromatografia em camada delgada. Brazilian Journal of Development. 7(1), 3008-3012. https://www.brazilianjournals.com/index.php/BRJD/article/view/22859/18335

Urry, L. A., Cain, M. L., Wasserman, S. A., Minorsky, P. V., \& Orr, R. B. (2021). Campbell Biology, (12a ed.), Pearson Education, Hoboken.

Voet, D., Voet, J, G., \& Pratt, C. W. (2016). Fundamentals of Biochemistry: Life at molecular level, (5a ed.), Wiley. 